\title{
Research on the Countermeasures for the Design and Construction Quality Control of Indoor Water Fire Fighting System
}

\author{
Chunyi Duan *, Chen Hong \\ Guangxi Polytechnic of Construction, 33 Luowen Road, Nanning, 530000, China \\ * dcyjoyce@126.com
}

\begin{abstract}
Water and fire protection design in buildings is a very critical part of construction projects. The main purpose is to effectively prevent fire hazards, and to conduct fire control in a timely manner when a fire accident occurs suddenly. The related design is very critical. Requires relevant workers to attach great importance to it, strengthen the design of upgrading water supply and drainage firefighting facilities, and strictly control the construction quality to ensure the safety of residents' lives and property. Therefore, the article integrates the actual situation of the construction project, focuses on explaining the problems that should be paid attention to in the water supply and drainage and fire protection design work of the building, and proposes effective measures to control the construction quality, hoping to provide some help to relevant workers.
\end{abstract}

Keywords: Water and Fire Protection Design in Buildings; Strictly Control the Construction Quality; Fire Protection Design Work; Effective Measures.

\section{Introduction}

The water supply and drainage and fire-fighting facilities in buildings are the key components of the entire fire-fighting system. Therefore, relevant workers are required to attach great importance to them regardless of whether it is during the design work period or the construction period. Factors are fully considered to strengthen and improve the quality and effectiveness of its construction. At present, the country attaches great importance to the related work of fire protection facilities, and puts forward strict requirements on its construction standards, which increases the difficulty of design work and construction operations. Therefore, it is necessary to ensure the construction quality of water supply and drainage and fire protection facilities in construction projects. It is required to clarify the actual potential hidden dangers, and at the same time use practical and effective measures for effective management and control to ensure safety, stability, and reliability in practical applications.

\section{Issues that should be Paid Attention to in the Current Building Water Supply and Drainage and Fire Protection Design}

At present, in the design of water supply and drainage and firefighting pipelines in national construction projects, the more common application material is plastic pipes. It has many advantages, its performance is more stable, the flow resistance is smaller, and the installation operation is more convenient. The material of the pipe itself is low in cost and can save a lot of resources. However, plastic pipes also have obvious disadvantages. For example, they have poor heat resistance. If the indoor temperature is high, the application of plastic pipes will have many safety hazards, requiring relevant workers to pay attention to the design [1].

The country has clearly stated in the design specifications for water supply and drainage and fire protection that when designing plastic water supply and drainage pipes, they cannot be used in practical applications near the stove. The distance needs to be greater than $0.4 \mathrm{~m}$, and the distance between it and the edge of the gas water heater cannot be less than $0.2 \mathrm{~m}$. In the process of design and construction, if relevant regulations and specifications are not effectively met, effective measures must be used for protection. The practical application of plastic water supply and drainage pipes in construction projects has great advantages, but there are also many disadvantages, mainly including 
poor pressure resistance and poor fire resistance. Therefore, super high-rise buildings higher than $100 \mathrm{~m}$ and fire protection requirements It is not advisable to use plastic pipes in tall buildings. You can choose to use some cast iron pipes with flexible connections. It is clearly stipulated in the design specifications that the gravity flow drainage system generally needs to choose a standardized form of building drainage pipe, and the single weight of super high-rise buildings can use pressure-bearing plastic pipes or metal pipes. Therefore, it is necessary to integrate the actual conditions of the construction project to rationally design the water supply and drainage and fire protection facilities, and to strictly follow the relevant regulations and standards for construction quality control, to ensure the safety, effectiveness and reliability of the water supply and drainage and fire protection design schemes in the construction project. And so on to lay a solid foundation [2].

\section{Technical Points in the Water Supply and Drainage, Fire Protection Design and Construction in the Building}

In order to ensure the design and construction quality of water supply and drainage and fire protection facilities in buildings, construction companies must actively incorporate modern technical means, strengthen effective management and control of actual construction, and strengthen the construction quality of construction projects [3].

\subsection{Automated Fire Extinguishing}

Automatic fire extinguishing technology is a number of components such as temperature control alarm equipment, detection equipment and fire extinguishing equipment installed in current construction projects. If a fire occurs, it can achieve the goal of automatic fire extinguishing. In the actual development of design work, design workers must fully integrate with the implementation of the automated sprinkler system, and give full play to the advantages of automated fire extinguishing. The designer must ensure that the alarm device in the automatic sprinkler system meets the scientific and reasonable requirements, and at the same time realizes accurate and clear alarms, and in essence ensures its orderliness and safety in the entire building [4]. In the process of designing sprinklers, designers must follow the overall layout of the building, and reasonably control the design and installation positions, to avoid problems that the distance between the sprinklers and the beam is too large or too small. When designing the automatic sprinkler fire extinguishing system for the basement of high-rise building projects, it is necessary to comprehensively consider the maximum fire intensity and strengthen and improve the fire extinguishing quality and effectiveness of the fire extinguishing system.

\subsection{Fire Hydrant Settings}

In the actual design of fire-fighting devices in construction projects, designers must integrate the actual situation to clarify the actual number of fire-fighting facilities. In the actual design of indoor fire hydrants, it needs to be able to meet the actual needs of the outdoor water pipe network. The number of outdoor water pump adapters and fire hydrants are required to be the same, to essentially ensure that all fire hydrants meet the relevant design requirements. In the process of designing the indoor fire-fighting pool, follow the high-pressure water supply system to implement secondary pressure to avoid many problems of insufficient water supply. For fire-fighting elevators, it is necessary to implement reasonable installations in accordance with indoor fire hydrants. When carrying out fire-fighting design work, the actual layout of fire hydrants must be carried out in accordance with the distance and location of the fire hydrants, to ensure that the length of the water column flushed out is sufficient, and at the same time, it must be the influencing factors are fully considered, such as doors, windows, and aisles. If the outlet pressure of the fire hydrant exceeds 0.5 $\mathrm{MPa}$, a corresponding pressure reducing device needs to be installed [5]. 


\subsection{Fire Water Supply}

When designing fire-fighting water supply related technologies in construction projects, it is necessary to integrate a lot of information such as the actual area and height of the construction project, and clarify the water consumption based on this. The country has relevant regulations in this regard. If the fire accident lasts for 3 hours, the fire-fighting water consumption indoors in high-rise buildings is $40 \mathrm{~L} / \mathrm{s}$, while the outdoor water consumption is generally $30 \mathrm{~L} / \mathrm{s}$. A transit water tank needs to be installed for every building in the building, and a frequency conversion pump is required between the two refuge floors to achieve pressurized water supply. For areas with greater fire risk, roof water tanks must be installed. In this way, water supply can be implemented based on gravity to ensure water supply pressure, and it can also essentially ensure the indoor safety of construction projects. It is necessary to conduct a comprehensive analysis and consideration of related matters. If necessary, it is necessary to design a fire-fighting pool circulating water pump and a diversion wall, which can not only reduce the cost of capital investment, but also help the actual development of subsequent management work and strengthen Improve the level of fire safety. When designing and constructing water supply in series, relevant workers must take into account the water supply and scope of fire trucks. For the case where the fire hydrant system is outside the scope of the fire truck, it is necessary to connect the adapter of the water pump.

\subsection{Fire Drainage}

The design of the fire-fighting water supply and drainage system in a building is a key component of the overall fire-fighting system. Therefore, when designing fire-fighting drainage-related design, it must be designed in accordance with the relevant requirements and standards promulgated by the state. When the drainage pipe is under the electrical pipeline, it is necessary to ensure that there are pressure pipes to avoid non-pressure pipes. In the process of designing the fire elevator shaft, it is necessary to choose drainage facilities lower than the foundation pit. Reasonable design of the tube. Especially when designing the fire pump, the designer must connect it to the basement to ensure timely and effective water supply and drainage, and at the same time to enhance the important role of the sewage pump. Based on the actual design of the sump, it is also necessary to carry out a reasonable design of the drip. In the process of installing the drainage pump in the fire elevator, it is required to ensure the quality of its construction work, so that the actual role and value of the fire protection facility can be fully utilized [6].

\section{The Practical Application of Various Technical Points in the Fire Protection Design of Construction Projects}

If the design of the fire protection system of the construction project is facing a commercial and residential building, a water collection pit is set at the location of the pump room, and water-retaining and waterproofing devices are designed at the elevator entrance. In order to be able to meet the actual requirements of fire extinguishing operations, designers also need to design fire hydrants in each layer. When designing the roof of this construction project, a transfer water tank should be placed in the middle of the roof, and a booster pump water tank for pumping should also be equipped to ensure the effectiveness of firefighting. For outdoor design of fire-fighting pump adapters, in all floors, designers must also design alarm valves and sprinklers to meet the actual demands of building fire-fighting operations. Regarding the automatic spraying device, the opening temperature of the spray nozzle in the kitchen is generally $950^{\circ} \mathrm{C}$, while the opening temperature of the spray building in public places and rooms is generally $650^{\circ} \mathrm{C}$.

\section{Conclusion}

The indoor water supply and drainage and fire protection design work of the construction project belongs to the solid foundation of the entire project. The relevant workers are required to attach great 
importance to the construction quality and strictly control the construction quality. Only by making multiple efforts can the overall quality of the construction project and its actuality be ensured. With the safety, stability and reliability in the application process, all fire-fighting facilities can give full play to their role and value, provide guarantees for the vital interests and personal safety of all residents, and lay a solid foundation for the modern development of a harmonious society.

\section{Acknowledgments}

This research is supported by "Research and Practice on the Training Mode of Applied Talents of Fire Engineering Technology Specialty in Higher Vocational Education Based on Service Industry Structure". (ID: 2019A030).

\section{References}

[1] Jian fang Lai. Talking about the design and construction analysis of building indoor water supply and drainage fire protection [J]. Sichuan Cement. 2018(12).

[2] Wei Zheng. Building indoor water supply and drainage fire protection design and construction quality control measures [J]. Housing and Real Estate. 2019(25).

[3] Shirin Wan. The key to building interior water supply and drainage fire protection design and construction technology [J]. Building Safety. 2014(11).

[4] Donghu Pan, Kai Zhao. A brief introduction to the design and construction technology of building indoor water supply and drainage fire protection [J]. Jiangxi Building Materials. 2017(01).

[5] Jia Wu. Talking about the design measures of building indoor water supply and drainage fire protection [J]. Heilongjiang Science and Technology Information. 2014(15).

[6] Xungang Zhuang, Weiping Su. A brief introduction to the design and construction technology of building indoor water supply and drainage fire protection[J]. Low-carbon world. 2017(11). 